\title{
IDEALES MORISCOS EN UNA CRÓNICA DE 1344
}

\section{Advertencia inicial}

En el año de $195^{\circ}$ atrajo mi atención la Crónica de Alfonso XI contenida en el ms. 1015 de la Biblioteca Nacional de Madrid, pues resultaba ser muchísimo más extensa que la versión regia escurialense publicada por Cerdá en 1787 . El ulterior cotejo de 22 manuscritos de la Crónica me hizo ver que las importantes variantes en ellos contenidas respondían a la existencia de versiones diferentes, hasta hoy desestimadas, y que estas versiones se agrupaban en dos grandes tipos, representando dos redacciones distintas de la Crónica. En fin, pude comprobar que la verdadera Crónica de Alfonso XI está inédita, y había permanecido, hasta el momento, desconocida ${ }^{1}$. La que se imprimió en el siglo xvi y luego en el xviri no es sino una Abreviación ajena al autor.

La inédita Gran Crónica de Alfonso XI, escrita en 1344, constituye una verdadera revolución en el género histórico, pues rompe con la seca concisión tradicional en la historiografía cristiana para darnos palpitante y coloreada la vida toda de aquella época, con una riqueza de pormenores y una viveza dramática totalmente extrañas a las demás crónicas².

También resulta excepcional su vasto y profundo interés por el campo musulmán, al que presta detenida atención, tanto para darnos el reverso de la historia fronteriza, como incluso en sus asuntos de orden interno. Este interés no se limita a lo peninsular granadino; la historia puramente africana de los benimerines se extiende por

${ }^{1}$ En 1348 fuć versificada por el Poema de Alfonso XI. Con posterioridad sólo los historiadores portugueses Roi de Pina, Duarte Nunes de Leão, Acenheiro y subsiguientes, conocieron directa o indirectamente la Crónica amplia originaria (y en versión mejor que la por mí utilizada). En Castilla la Abreviación, copiada en múltiples manuscritos durante el siglo xv y editada después en el xvi, reemplazó totalmente a la redacción primitiva. Sobre la Gran Crónica de Alfonso XI inédita versa mi tesis doctoral (Madrid 1951), estudiándola desde los puntos de vista crítico, histórico y literario.

2 Véase Diego Catalán, El poema cronistico y la Crónica poética de Alfonso $X I$, cap. vi (anejo de $R F E$, en prensa); y "La oración de Alfonso XI en el Salado", $B A H, \mathrm{CXXXI}, 195^{2}$, págs. 253-259. 
más de cincuenta capítulos de la Crónica. No en vano había actuado Alfonso XI como rompeolas frente al último intento africano de invadir Europa, y cerrado la puerta a toda tentativa posterior con la "llave" de Algeciras, la "ciudad postrimera de Europa", avanzada sobre África.

El testimonio de un contemporáneo, tan atento al mundo musulmán como nuestro cronista regio, acerca de la existencia en la primera mitad del siglo xIV de una comunidad cristiano-islámica en el sentir la vida, así como su juicio terminante en cuanto a la realidad de una ley divina por cima de la división en credos irreconciliables, merecen a mi entender la atención de la Historia.

\section{El ideario caballeresco entre los moros}

En la Crónica de Alfonso XI el moro granadino o africano tiene un ideario caballeresco en todo semejante al del cristiano. La suprema aspiración del caballero de una y otra religión es la inmortalización del nombre en la Historia, el "ganar honra y prez" en el mundo, dando que hablar para siempre. En los discursos y arengas de los caballeros castellanos son frecuentes frases como ésta: “. . . e ganarían honra y fama de que hablarían por tiempos del mundo, que quedase por heredades a los que dellos veniesen" (ms. 1015, cap. 35o); pues bien, en perfecta correlación vemos a don Clariffe el Alárabe aconsejar a Alboacén que se retire del cerco de Tarifa y espere una ocasión mejor, ya que así podrá correr la frontera y volver a Marruecos "con gran honra", "e el vuestro precio e la vuestra honra e fama sería nombrada fasta la fin del mundo" (cap. 327). A su vez el rey de Granada, para sustentar la opinión contraria de enfrentarse con los reyes de Castilla y Portugal, invoca razones semejantes: "en este lugar vos acabe fama e honra para siempre, o pérdida e desonra por tiempos del mundo" (cap. 345); y pone de ejemplo a los reyes enemigos, dándonos así una muestra de esa equiparación en el espíritu de moros y cristianos que venimos reseñando: "tomad exemplo de aquestos reyes christianos que no tienen la terçia parte de cavallería que vos tenedes e bienen todos con alegres coraçones por tomar muerte por la fama deste mundo e cobralla para siempre" (cap. 345).

El mayor interés de la Historia es por tanto perpetuar en escrito los buenos hechos de los reyes y de sus vasallos para que, "como quier que los cuerpos aquí fallesciesen, las buenas hazannas e prohezas e nobles famas ... durasen por siempre, e fuesen vivos sus loores en los coraçones de los que los oyesen o leyesen, por que en ellos pudiesen tomar enxemplo los príncipes e los caballeros e las otras gentes para bien fazer"'. Así, no es de chocar que el propio rey de Castilla ofrezca

3 Estas palabras forman parte del Prólogo de la Crónica de Alfonso XI, contenido en una familia de manuscritos de la Abreviada (Escorial, Z-III-8; Y-III-1o; 
en dos ocasiones al caballero que realice cierta hazaña que "por esta razón lo faría poner en Corónica, por que por todos tiempos del mundo quedase la su fama renobada" (cap. 180) nadino recuerde a su aliado, el rey benimerín, la fama alcanzada por su antepasado Abojuçaff: "déveseos de membrar ... cómo christianos e moros lo ternían puesto en libros por las vondades que hizo" (cap. $345)$.

La hereditariedad de la honra es concepto básico en que se fundamenta la nobleza de sangre; la fama que adquiere un caballero queda "por heredad" a sus descendientes, y éstos están obligados a no desmentirla. Véanse por ejemplo las palabras de Ruy Gonzalo de Castañeda negándose a abandonar Tarifa en momentos de peligro: “. . .que los de su linage siempre hizieran por hazer mucho servicio a los reyes de Castilla..., e que él ansí lo quería hazer..., que allí quería servir a Dios e al rey, e ganar fama si atal tiempo viniesse para sí e para su linaje" (cap. 29o). Con ideas similares el rey de Granada argumenta a Alboacén: "déveseos de membrar cómo sodes acabado de linage e de alta sangre e de dó venistes, e ménbresevos del rey Abdalfaque, quán acabado rey fué en esta vida, e del rey Abojuçaff, su hijo, quántas vegadas pasó esta mar..." (cap. 345).

En fin, esta honra, difícil de adquirir y mantener, se pierde, según la opinión del rey moro granadino, con gran facilidad, siendo imposible luego el recobrarla: “. . . todo el mundo hablaría de vos o vos tendría por el más menguado rey que nunca fué en el mundo; e por bien que después hiziésedes, no vos lo ternían en nada; porque todo sería perdido por una cosa tan sólo que hiziésedes contra vuestro estado" (cap. 345). Y esta misma idea tenía Alfonso XI, quien argumentaba días antes contra los suyos: "en el tiempo en que estamos, más culpado es el hombre de un hierro que le viene, que de cient bienes que aya hecho"; "que parasen mientes, según havía dicho el rey Salomón en una razón que dizía anssí: que todo el comienço del hombre es ansí como la raýz del árbol, e que la sima es como la flor que paresce bien; assí como el home en este mundo que a buen comienço e no buen acabamiento, no vale su comienço ni quanto hizo; si no hoviere buen acabamiento es perdido como si nunca fuese hecho" (cap. 337)

Y-II-12). Se inspira en el prólogo de la Primera crónica general, suprimidas algunas partes y ampliadas otras.

${ }^{4} \mathrm{El}$ segundo ofrecimiento en todo paralelo sólo lo conozco a través de la versificación del Poema $\left(15^{6} 4^{-1} 5^{66}\right)$ :

${ }_{15} 66$ En el mi cuento granado / yo lo cuydo de poner, que siempre sea nombrado / el buen fecho que fezier.

- Para más detalles véase mi tesis doctoral, págs. 92-100. Un capítulo sobre "La lealtad y la fama" formará parte también de un librito que preparo: "Quien 
El espíritu caballeresco entre los moros se manifiesta en otras concepciones a más de ésta citada de la fama terrenal; los caballeros benimerines tenían también su orgullo de hidalguía, expresado claramente en la Crónica. Por ello consideraban tan deshonroso pechar dineros al rey como cualquiera de aquellos hidalgos castellanos, que, según la leyenda, presentaron atada a las puntas de las lanzas la moneda que el rey quería cobrarles: "No he haver que vos dar, y aunque lo oviese, nunca os lo daría; y tengo que faze locura el cavallero que da algo al rey, ca con derecho los reyes deven dar a ellos que no pedilles como villanos pecheros" (cap. 227), replica en la Crónica el infante Botexefín al rey Aboamón (o Aboacino) cuando le pide ayuda económica para sostener el cerco de Bugía.

\section{El amor y la caballeria entre los moros}

Mucho más interesante que todo lo hasta aquí citado es la escena en que se nos muestra a Alboacén, empapado de los más notables conceptos del noble oficio de caballería, haciendo la apología del amor y del caballero enamorado. Estamos en el real de Tarifa. Acaban de llegar los mensajeros cristianos anunciando a los reyes moros que Alfonso XI de Castilla y Alfonso IV de Portugal acuden a presentarles batalla. Alboacén reúne entonces consejo, y entre los diversos pareceres está el de Mahomad Diche, señor de Marcameda, quien propone enviar las reinas y demás dueñas con los niños a Algeciras para ponerlos a salvo de los azares de la batalla.

A ello replica el propio rey de Benimerín diciendo cómo todo el mundo pensaría, al saber aquello, que él no era capaz de defenderlas, y además (cap. 343):

[A:] Bien sabían quántos esfuerços de cavallerias buenas hacian los homes por amor de las mugeres: lo uno, con amor que les fuerça e que les da gran ardimiento para pelear viendo do ellas están, e lo ál, que los que no son amados dellas, hazen mucho que sean amados, e por esto olvidan tierras e viçios $\mathrm{e}$ pierden duelo de los sus cuerpos por hazer más que otros omes. E otrosí que el que tiene mujer y hijos querrálos deffender e hazer mucho por llebar la honrra e lo mejor de aquel que la non tuviere. [B:] E que el que muger non tiene en tal lugar, siempre sospira $(\mathrm{n})$ por ella si la bien quiere, e si está en batalla, el coraçón tiene en ella; e el que es malo, olvida la vergüença del mundo, que siempre puede pasar bien y plazer con su mujer e con sus hijos a quien bien quiere(n). E esta cuenta haze el malo vil e traydor a Dios e al mundo, ca el bueno enantes querría mil

bien sivve bien desirve y quien bien desirve bien sirve". El problema de nobleza y realeza a través de la Gran Crónica de Alfonso XI y las obras politicas de don Juan, hijo del infante don Manuel. 
muertes para sí e su muger e sus hijos que desamparar su natural señor e desamparar el campo ni ser desdicho e mal aventurado. [C:] E por esto venga el rey don Alonso de Castilla, que las mugeres no las embiaré a ninguna parte, e antes mando a todas aquel día de la batalla se apuesten todas como parescan a sus maridos e a los sus entendedores muy hermosas, e que dellas aya coraçones para hazer todo bien por las deffender si atal tiempo viniesen; que por cierto el amor es una tal graçia qual dió Dios, que no a home que la aya que nunca mal hecho pueda hazer, $e$ que cometerá un enamorado hecho tan alto e tan maravilloso que lo non osarán acometer çinco homes que enamorados non sean. [D:] E por esto las mugeres aquí quedarán, si yo aquí estubiere; e si fuere a otra parte, conmigo yrán; y si yo fuere el vençedor, ellas lo pasarán bien, e si nos fuéremos vencidos o muertos, no havemos menester mugeres, e las que mataren yrán salbas, y hallarlas hemos connusco en la Casa Sancta del gran profeta Mahomad.

La costumbre de llevar las mujeres e hijos a la batalla como medio de obligarse los caballeros a combatir como buenos, pues la derrota significaría el cautiverio de toda la familia (razón $B$ ), era costumbre bastante general a muchos pueblos bárbaros; ya Tácito lo señala respecto a los germanos. Intención semejante tenía la de llevar grandes riquezas al campo de batalla. En el Alexandre, durante el consejo reunido por Darío antes de la batalla, hay una discusión muy curiosa sobre este punto. Un griego que se ha pasado al campo enemigo aconseja que las grandes riquezas que habían sido allí llevadas en "azémilas, e carros e camellos cargados" se lleven a Damasco por si "se torciere el viento" de la batalla. A pesar de la indignación de los persas, Darío acepta este consejo, aunque, lo mismo que Alboacén, no consiente en retirar las mujeres (copla 933):

Pero es consejo ovieron a tomar:

fezioron los tesoros a Damasco levar;

mas ovieron las dueñas con el rey a fincar,

non quisioron las leys antiguas quebrantar.

Pero lo que verdaderamente tiene importancia en el discurso de Alboacén es la primera razón $(A)$ aducida por Alboacén: la superioridad del caballero enamorado, razón recogida de nuevo y ampliada al final del razonamiento $(C)$. También el Cid dice a su mujer e hijas: "créçem el coraçón porque estades delant" (1655), pero el espíritu del discurso de Alboacén es mucho más caballeresco; semejante, y aun mayor, que el denotado por la Parlida II, 21, 22: "los caballeros ... por que se esforzasen más, tenían por cosa guisada que los que hobiesen amigas que las ementasen en las lides, porque les cresciesen más los corazones et hobiesen mayor vergüenza de errar". 
Ahora bien, esta alabanza del amor y el caballero enamorado, propia de un caballero andante, ¿es posible ponerla en boca de Alboacén sin cometer una grave falta contra la Historia? Nos planteamos ahora por primera vez, al llegar al término de esta exposición. una pregunta que puede extenderse a todo lo anterior: este espíritu caballeresco que el cronista, preludiando al romancero morisco, supone en el musulmán, tanto granadino como africano, ¿responde a la realidad de la época o es un trasplante absurdo del ideario cristiano del siglo xiv al mundo musulmán? No soy arabista, así que me faltan conocimientos suficientes tanto para afirmar una cosa como la contraria. Sin embargo, mi opinión es que todos aquellos discursos en que hemos hallado estos rasgos caballerescos, si no estrictamente verdaderos, son al menos verídicos. Me resisto a creer que el cronista, muy interesado por todo lo moro (incluso lo puramente marroquí), desconociese la vida musulmana y trasplantase arbitrariamente al mundo musulmán un modo de sentir la vida típicamente cristiano, en aquellos tiempos en que la comunicación entre los dos mundos era tan activa, según muestra la constante presencia de cristianos, temporalmente expatriados, en todo suceso fundamental de la historia marroquí.

En las páginas que siguen tendremos ocasión de ver cómo la diferencia de religión no representaba un telón de acero en las relaciones entre la cristiandad española y el Islam; por el contrario, existía una vida en común que unía a ambos mundos, e incluso sobre ambos descansaba una ley moral "que Dios estableció entre los hombres en comunalmente" por encima de los credos religiosos. Veamos en detalle la actitud del cronista ante el moro enemigo.

\section{El moro visto con simpatia}

El cronista de Alfonso XI no muestra jamás desprecio alguno hacia el enemigo musulmán; por el contrario, sabe bien que la gloria del enemigo vencido revierte sobre su vencedor y por ello tiene gran interés en ensalzar al máximo la figura del rey benimerín Alboacén: "el buen Alboaçén, de quien habla este libro, fué uno de los reyes moros el mejor que nunca se vió en cavallo nin tomó azagaya en mano; y en el comienço de su reynado se fizo dudar a los suyos y a los christianos, anssí que de luengas tierras temían la su lança e preçiavan la su cavallería; y luego fué rey muy grande, y con gran saber se fizo amar a los suyos y se apoderó de los sus reynos como nunca fué rey en la partida de Áffrica fasta en aquel tiempo" (cap. 220).

I a alabanza se extiende, para mayor honra de Alboacén, a toda su dinastía: "El rey abdalfaque fué el primero de los reyes de Benamarín, c lué buen rey en su ley y muy esforçado, y dió çima a grandes fechos y llamáronle los moros Esmeril de los reyes, que querían dezir 
Espejo de los reyes; e aun, según dice la Grande Historia de África ${ }^{6}$, fué llamado rey Sancto; y esto fué porque en su vida nunca fué vençido... E bien anssí fueron todos los otros reyes muy buenos que descendieron deste linage ...", etc.

Esta glorificación del rey africano enemigo tiene su complemento en la notable simpatía con que se mira al moro en desgracia: "En aquel lugar hallaron muerto al infante Abomolique que ganó a Gibraltar y corrió la frontera ... , e assí yacía desamparado e vilmente que no havía home que lo viesse que dél no oviesse duelo, como quier que fuesse moro" (cap. 265). Y con verdadero dolor sigue efectivamente el cronista la trágica suerte de este infante, primogénito de Alboacén, que en la cumbre de su gloria y por su soberbia irre flexiva cae víctima de una sorpresa cristiana, escribiendo a este propósito una de las mejores páginas de su Crónica ${ }^{\top}$.

\section{El héroe moro exaltado}

EI historiador de Alfonso XI tiene una preocupación constante por destacar como virtud esencial en el caballero la lealtad a su rey y señor natural. Al vínculo feudal del vasallaje que podía ser roto por el vasallo "cada que quisiere" (según frase de don Juan Manuel), el cronista antepone el vínculo de naturaleza, de deber para con la patria simbolizada en el rey "que todos los hombres son tenidos de guardar". La importancia dada a esta concepción hace que la fidelidad hazañosa sea exaltada repetidamente no sólo entre los naturales de Alfonso XI, sino entre los vasallos de un rey enemigo*. Pues bien, lo que ahora más nos interesa es que no se detiene ni aun por barreras de religión: la glorificación del héroe y del buen vasallo moro es igual de entusiasta. Veamos algún ejemplo. Cuando el infante Alicantar (o Alicazar), sobrino de Alboacén, hace frente con pocos caballeros a una hueste que viene a sorprender el real de su primo Abomelique, el cronista señala admirativo: "se deffendía atan maravillosamente, que todos aquellos que lo veían se hazían maravillados" (cap. 264).

En otra ocasión la acción de unos vasallos moros que defienden una villa contra los cristianos se considera incluso como ejemplar: "e hizieron rostro en el lugar que derribavan los ingenios, ansí que

"En el cap. 344 vuelve a citarse esta historia especificando el nombre diel autor: "dixo el maestro Sujulberto que compuso la Historia de Áffrica ..." Ignoro si se trata de un historiador cristiano o de uno musulmán.

- Véas: para este pasaje el poema cromistico..., alp. vul del Trailer.

* El cronista se detiene a consalzar la hazaña infructuosa de un peón portugués que al\%ó en la derrota el pendón, abandonado por el alférè, "según bueno si fuere acorrido de buenos", y, sostcniéndolo, murio a manos de los castellanos. "e Dios por su merced le perdone, porque cierto él lo fizo bien" (cap. 193). 
no hazía hallí mengua el muro por bondad de los moros que lo bien defendían con gran trabaxo, por guardar bergüença e lealtad, que todos homes son tenidos de guardar. $\mathrm{Y}$ atales fueron los moros desa begada por ganar honrra e prez, que olvidaron la muerte y estubieron en aquel lugar a guisa de buenos" (cap. 110).

\section{El traidor moro ante Dios}

Esta lealtad "que todos homes [moros y cristianos] son tenidos de guardar" es una ley moral respaldada por Dios, por eso el cronista considera traidores a Dios aquellos moros que como traidores se comportan en el munde. El infante Aboalí se rebela contra su padre Alboçayde: "la qual cossa hizo el infante no guardando a Dios ni guardando a su padre lo que devía" (cap. 215). El infante Botexefín trama la muerte de su padre al ser deshonrado por él en público, "y ansí lo hizo el traydor, que sea perdido con Judas" (cap. 227). Habraén el Beodo, hijo de Ozmín, cuando el rey de Granada quiere agarrarle de la barba, hiere a su señor con la espada, y lo mismo hacen otros caballeros, "traydores a Dios y al mundo, los que mal siglo ayan sus ánimas" (cap. 149).

Obsérvese en estos dos últimos casos cómo el cronista desea la especial condenación para estos traidores, lo cual lleva a suponer que consideraba posible la salvación (o al menos la no condenación) de un buen musulmán, afirmación ésta que, aunque profundamente cristiana, sería verdaderamente extraordinaria.

Desde luego Dios da el merecido castigo a la traición con su política providente: "y por esta trayción que hizieron los moros de Granada en matar a su rey e a su señor fué la cassa de Granada tirada de su honrra e derribada de su estado y los moros mal andantes; y las tierras no ovieron sombra según que antes havían, e después plugo a Dios que vengó la muerte del rey de Granada el bienaventurado rey don Alonso de Castilla" (cap. 149).

Aquí apunta una idea de gran interés: la concepción cronística de la guerra de reconquista. Ella nos ilustra mejor esta equiparación de moros y cristianos.

\section{La providencia de Dios en la guerra}

Fn las guerras, sea entre cristianos, sea con moros, Dios es quien da la victoria: "e fué la boluntad y la merced de Dios, en quien es todo el poder cumplidamente, que bençieron los christianos" (cap. 10); "... a quien Dios quiso dar aquel día vitoria, e la honrra de aquella batalla" (cap. 10); "por Dios que les quiso haçer merced y dar la honra del bençimiento" (cap. $3^{8}$ ). E incluso a los moros sobre los cristianos: "Ozmín, el buen moro, a quien Dios dió dicha e bentura sobre los infantes en la Bega do fueron muertos" (cap. 61). 
Pues, según se nos dice, "la bentura no es otra cosa si non graçia que Dios pone en quien es la su merced, que de otra guisa quien dize bentura, es palabra perdida" (cap. 37).

Dios es quien sugiere los ardides: "Dios, de quien biene toda la saviduría, amostró esta vez a los de Guipuzcoa una maestría sotil"; "e esto fue por maestría simple y graçia que Dios quiso dar al bienaventurado rey don Alfonso" (cap. 37). La guerra, por lo tanto, no es sino un juicio de Dios que da como merced la victoria a quien corresponde por sus méritos tenerla: los navarros deciden atacar Castilla e incluso apoderarse del rey-niño castellano, aprovechando la muerte de los tutores en la Vega de Granada, "de la qual raçón no plugo a Dios, e quiso quebrantar sus sovervias y las palabras baldías que dezían contra su rey terrenal que Dios puso sobre la bentura" (cap. 37).

Del mismo modo, la paz sólo viene traída por Dios: "E así como Dios tovo por bien de dar a este rey don Alfonso los regnos de Castiella et de León, seyendo muy niño; et después le dió manera por que los podiese apoderar, tovo por bien de traer a su mano et a su poder este don Alfonso [de la Cerda], que fué el mayor contrario que los reyes su avuelo et su padre ovieron en sus vidas" (ed. de Cerdá, cap. 95, pág. 196).

Toda esta concepción de la guerra nada tiene de particular, sobre todo en la Edad Media. El propio don Juan Manuel insiste en el Libro de los estados repetidas veces en ella: "Ca debe creer verdaderamente que entre todas las cosas del mundo que Dios tiene en su poder, de las más señaladas es las guerras et las lides, ca esto, sin dubda ninguna, todo se face segund la voluntad de Dios. Et pues Dios es derechurero, forzadamente conviene que se tenga con el que tiene derecho, et que le ayude" (cap. 71)9.

8. Dios, "juez medianero" por

encima de las dos religiones

Pero lo curioso es que tal concepción de la guerra como ordalia o juicio de Dios se aplica igualmente a las luchas de reconquista, no ya sólo al suponer que Dios da a menudo la victoria a los infieles por pecados de los cristianos, sino, lo que es más importante, porque Dios, siendo "derechurero", considera que el derecho está del lado musulmán. Este caso lo vemos plenamente desarrollado en la Crónica con motivo de la muerte de los infantes don Pedro y don Juan en la Vega granadina y la derrota del ejército cristiano que mandaban.

- Véase el artículo de Manuel. Torres, "El arte y la justicia de la guerra en el Libro de los estados de don Juan Manuel”, CyR, núm. 8 (nov. 1933), págs. 49 y 53 y sigs. 
Don Pedro había firmado una tregua con Granada, por la que los moros le pagaban parias. Dentro aún del plazo, el Papa, atendiendo peticiones del infante, le otorga los derechos de cruzada ordenándole bajo pena de excomunión que rompa la tregua y no pacte con los moros. El Infante, muy gozoso, se lo. anuncia al rey granadino y le devuelve las parias; el rey moro, lleno de pesar, dice: "Yo moro soy y él infante christiano; yo quiero guardar la verdad que Dios estableçió, y el aver que yo di al infante no lo quiero tomar, mas quiero guardar la carta de la fialdad que me dió por esta raçón. Y el infante me tiene tuerto, ca destruyóme mis tierras y corrióme y matóme mis moros, e sobre este mal que me hizo le di parias por que me dexase vevir en mis tierras en paz, e agora quiere quebrantar la fe y la verdad que puso conmigo. E pongo a Dios en el comedio que sea juez medianero y administre justicia e milagro sobre tal fecho, por que todos los del mundo sepan que es fee y berdad" (cap. 19).

La guerra comienza, los dos infantes don Pedro y don Juan marchan hacia el corazón de Granada con un poderosísimo ejército. Pero van mal avenidos, deseando cada uno la muerte del rival: "mas Dios, que es padre y poderoso señor y es hazedor y deshazedor de todas las cosas, no quiso que se cumpliese ninguna cosa de lo que ellos tenían propuesto en sus coraçones" (cap. 20). Cuando ya ante Granada sólo se oponían a su gran ejército, de nueve mil caballeros e innumerables gentes de a pie, cinco mil caballeros moros, sobreviene el desastre: los cristianos antes de empezar la lucha se desorganizan; se mata, por culpa de los suyos, el infante don Pedro; las gentes huyen; muere el infante don Juan y la derrota es inmensa.

El cronista comenta: "Ya Dios tenía dada su sentencia contra los christianos, e la rueda de la ventura era ya buelta de mala manera, de guisa que sin contienda e sin pelea e sin feridas ningunas de christianos ni de moros [sic]. E si fué boluntad de Dios, ho por los pecados de los christianos, o por las malas intenciones de los dichos infantes muertos; e ansí se entiende que fué milagro e justiçia de Dios, ca Dios, en que es el poder todo cumplido, nunca se paga si non de berdad, e nunca hizo justicia sin meresçimiento, e por ende él supo qué hizo e consintió" (cap. 21 ). Y antes había ya anunciado: "e de todos estos hechos que hizo este infante don Pedro no hallan los hombres que le [el ms.: se] retraygan sino éste solo: en quebrantar las pazes que abía puesto con el rey de Granada e su berdad, e pasar la fe [e] fialdad que Dios estableçió entre los hombres en comunalmente; e aún sospechan los homes que ésta fué la ocasión por que este infante fué muerto, según adelante oyredes" (cap. 18).

F. cronista oficial de Alfonso XI no puede ser más terminante: hay una ley de Dios por encima de las dos religiones, y Dios "administra justicia y milagro" sin atender a la religión, sino a la verdad de cada uno. $\mathrm{Y}$ nótese que el juicio es tanto más significativo cuanto 
que don Pedro no hacía sino cumplir bajo pena de excomunión órdenes del Papa.

\section{Cruzada y reconquista}

Sin llegar tan lejos como el "estoriador" del rey, don Juan Manuel tiene unas observaciones notables en el Libro de los estados contra el juicio simplista de que todo aquel que muere luchando contra los moros tiene salvada su alma: "non debedes creer que todos los que mueren en la guerra de los moros son mártires nin sanctos; ca los que allá van robando et forzando mujeres et faciendo muchos pecados et muy malos et mueren en aquella tierra, nin aun los que van solamente por ganar algo de los moros, o por dineros que les dan, o por ganar fama en el mundo, et non por entención derecha et defendimiento de la ley et de la tierra de los cristianos, éstos, aunque mueran, Dios, que sabe las cosas escondidas, sabe lo que ha de seer de estos tales". Sólo los que van "en verdadera penitencia et con derecha entención", poseídos de sincero espíritu religioso, "siempre vencen et son bienandantes, et aunque los moros los maten siempre ellos fincan vencedores. Ft así la primera cosa que home ha menester para vencer los moros... es que los que fueren contra los moros vayan como dicho es; et Dios, por que ellos lidian, lidiará por ellos, et serán siempre vencedores" 10 .

Américo Castro en España en su historia se refiere en especial (pág. 205) a este mismo pasaje, viendo, por el contrario, en la idea de reconquista del prócer un claro ejemplo de "guerra santa" por la que hasta los pecadores pasan a ser "derechos mártires". Fsta idea se extrae de una cita fragmentaria del razonamiento de don Juan Manuel: "et aun los pecadores que mueren et los matan los moros, muy mejor esperanza deben haber de su salvación que de los otros pecadores que non mueren en la guerra de los moros... si él muere en defendimiento et ensalzamiento de la sancta fe católica; et los que así mueren sin dubda ninguna son sanctos et derechos mártires; et non han ninguna otra pena sinon aquella muerte que toman".

No comprendo bien la cita de Castro. A mi parecer, el primer párrafo de don Juan Manuel por él transcrito no es sino una concesión para quitar crudeza al razonamiento inmediatamente anterior, arriba citado, que comienza: "non debedes creer que todos los que mueren en la guerra de los moros son mártires..." Y el segundo se refiere, desde luego, no a los pecadores, sino al no pecador que va a la guerra "en verdadera penitencia", como el santo rey don Fernando.

Don Juan Manuel no rechaza el valor de guerra santa que tenía

"BAAEE, vol. LI, pág. 324. 
la lucha anti-islámica, pero exige para ello, y esto me parece muy importante, que la guerra sea "derechurera": "tienen los buenos cristianos que la razón por que Dios consintió que los cristianos hobiesen recibido de los moros tanto mal es porque hayan razón do haber con ellos guerra derechureramente", pues "Jesucristo nunca mandó que matasen nin apremiasen a ninguno por que tomase la su ley, ca él non quiere servicio forzado". Es decir, es justa la guerra contra los moros, no por ser anti-islámica, sino por su carácter de reconquista: "et por esto ha guerra entre los cristianos et los moros, et habrá fasta que hayan cobrado los cristianos las tierras que los moros les tienen forzadas, ca cuanto por la ley nin por la secta que ellos tienen non habrían guerra entre ellos". Y, además, en el plano individual de los combatientes sólo será mártir aquel que vaya a la guerra como buen cristiano, "por que los que en ella murieren $h a$ biendo cumplido los mandamientos de Santa Iglesia sean mártires e sean las sus almas por el martirio quitas del pecado que ficieren"11.

En suma, la teorización de don Juan Manuel tiene bastante de común con los conceptos del cronista de Alfonso XI. Y es que los españoles, tras esos largos años de convivencia con los musulmanes, habían llegado a formarse, acerca de las relaciones entre cristianos e Islam, un criterio mucho menos simplista del que se tenía en el resto de la Europa cristiana ${ }^{12}$. De aquí el fracaso de todas las Cruzadas europeas a España, que necesariamente se desintegraban al chocar con la concepción española de la reconquista ${ }^{13}$, y de aquí también la falta de comprensión del Papado para los problemas de la cruzada espanola. Sobre este último problema son un buen ejemplo las exigencias que puso Aviñón al infante don Pedro antes de concederle en 1318 las tercias y las décimas de la recaudación eclesiástica en la propia Castilla, para su famosa campaña: no firmar treguas con los moros en tres años, durante los cuales debía llevar el infante la guerra personalmente; cautivar a todo sarraceno que no recibiese el bautismo en las tierras que ganase; hacer iglesias las mezquitas, etc. ${ }^{14}$

España había perdido la intolerancia religioso-racial que pervivía

11 Ibid., pág. 294a-b.

12 Esta olsservación fué hecha ya por Menéndez Pidal en La España del Ciid, pág. 675 de la ed. de 1929 (pág. 632 de la ed. de 1947): "Se ha dicho que la religiosidad española medieval fué anormalmente cxacerbada por efecto de la lucha antiislámica. Pero lejos de hallar nosotros aquí una religiosidad socavada por los vientos de África, la vemos precisamente en la Edad Media perder cierta intolerancia racial que se descubre antes en la época cristianobárbara". Últimamente, Américo Cası́ro, España en su historia, dedica un acertado capítulo a la Tolerancia española medieval, removiendo los fundamentos islámicos de este "hecho" notado (págs. 206 y 55).

${ }^{13}$ Ejemplo preeminente es la retirada de los cruzados ultrapirenaicos antes de la batalla de las Navas.

14 Véase Gmínez Soler, Aragón y Granada, 19o8, pág. 206 y nota. 
en Europa, y concebía la reconquista como una guerra nacional de recuperación de la que no había que excluir ninguna de las normas caballerescas que, como derecho de gentes, regían la guerra entre cristianos $^{15}$.

Diego Catalán Menéndez Pidal.

Chamartín.

15. Ajustadas ya estas páginas, he tenido ocasión de tratar por correspondencia con don Américo Castro acerca de los aparatados 8 y 9 de este artículo. Debo, pues, reducir a mera nota final las interesantes observaciones de Castro.

Nota al apartado 8.--El pasaje de la Gran Crónica referente a la muerte de don Pedro es para Castro una muestra valiosa del deísmo islámico trasplantado a la España cristiana: "El texto que me comunicas es una joya... Me impresiona casi tanto como la llegada de los documentos con la noticia de haber sido quemados los padres de Luis Vives por la Inquisición, y de haber asistido Vives a la sinagoga hasta la edad de 10 ó 12 años... El deísmo islámico (que $\Lambda$ sín llamó «indiferencia») se inyectó en las Partidas y en la vida del s. xiv..."

Nota al apartado 9.--En cuanto al texto de don Juan Manuel, Castro aclara su opinión de España en su historia (1948): "tu observación sería justa si yo tratara de D. J. M.; pero mi problema es España como sujeto de historia, no D. J. M. como sujeto de tales o cuales ideas. Para mí la historia son las obras, las construcciones logradas, lo durable digno de durar, etc. Trato de poner al descubierto el "mobiliario» de la "morada vital" como una estructura jerarquizada, como un conjunto de manifestaciones valiosas". "A mí no me interesa la totalidad del pensamiento de D. J. M., sino la presencia de la Guerra Santa como institución islámico-cristiana... Es evidente que quienes mueren después de robar y forzar mujeres, o por ganar dineros o fama, no mueren en defendimiento et ensalzamiento de la sancta fe católica. Es decir, que a mí no me interesa cómo matice... [D. J. M.] la idea de la Guerra Santa, sino la simple presencia de ella en España, cosa no observada antes, y que yo no observo por satisfacer ninguna curiosidad, sino para mostrar cómo la guerra cristiana está teñida de sentimientos islámicos... En suma, que cuando D. J. M. habla de "martirio" refleja el martirio de los musulmanes en la Guerra Santa" (México, 7 de octubre de 1953).

Por mi parte, creo que las palabras de don Juan Manuel pueden servir de testimonio de la presencia entre los hispano-cristianos del concepto de guerra santa, según señala Castro y ya anotó Menéndez Pidal (La España del Cid, ed. de 1947, pág. 637, nota: "sin duda ese sentimiento del martirio se forma en respuesta al concepto musulmán de guerra santa"); pero la lograda construcción de don Juan Manuel apunta sobre todo a poner los puntos sobre las ies en el concepto vulgar de mártir de la guerra santa, con una elevada idea, poco común, de lo que pueda ser "la sancta fe católica" y de lo que era una "guerra derechurera". 